\section{Mais Um Ano Difícil}

Finalmente chegamos ao fim de mais um ano difícil para todos.

Nesse cenário tivemos de fazer várias alterações para reduzir nossos custos. Dentre outras medidas, a periodicidade que era bimestral passou a ser trimestral, os números impressos foram drasticamente reduzidos e a Cerâmica Industrial passou a ser quase uma revista digital, nosso site foi reformulado e passou a ser hospedado em outro servidor mais responsivo e que se adapta a telas de celulares.

Mesmo com essas mudanças a atual situação econômica da Cerâmica Industrial não é confortável e seu futuro depende mais do que nunca do suporte dos patrocinadores.

Enquanto trabalhamos no sentido de assegurar a continuidade da Cerâmica Industrial apresentamos neste último número do ano mais uma série de artigos que abordam vários aspectos da indústria cerâmicas e esperamos contribuam para a atualização e aprimoramento profissional dos nossos leitores.

Aproveitamos a oportunidade para desejar a todos uma ótima passagem de ano e um excelente 2019.

Anselmo O. Boschi

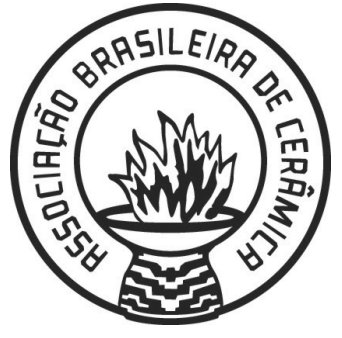

\section{Diretoria}

Presidente

Antonio Carlos de Camargo

Instituto de Pesquisas Tecnológicas do Estado de São Paulo S/A-IPT

\section{Vice-Presidente}

Edmilson Ricelli dos Passos

Elfusa Geral de Eletrofusão Ltda.

\section{Diretor Administrativo-Financeiro}

Juliana Marchi

Universidade Federal do $A B C$

Diretor de Publicações

Fernando Ortega dos Santos Centro Universitário FEI

\section{Diretor de Assuntos Empresariais}

Mauro Akerman

Akerman Desenvolvimento Profissional Ltda.

\section{Diretor de Assuntos Especiais}

Edgar Dutra Zanotto

Universidade Federal de São Carlos

\section{Diretor das Comissões Técnicas}

Ulisses Soares do Prado

Lining Representação, Consultoria e Projetos Ltda.

\section{Diretor de Comunicações}

Válquiria de Fátima Justo

Escola Politécnica da Universidade de São Paulo

\section{Diretor de Eventos}

Samuel Marcio Toffoli

Escola Politécnica da USP 